\title{
EFEITOS DO USO DA ISOTRETINOINA ORAL NA PAPILOMATOSE CONFLUENTE E RETICULADA: RELATO DE CASO
}

\author{
EFFECTS OF THE USE OF ORAL ISOTRETINOIN IN CONFLUENT \\ AND RETICULATED PAPILLOMATOSIS: CASE REPORT
}

Millena Nóbrega Dantas de Freitas ${ }^{1}$

Lívio e Vasconcelos do Egypto ${ }^{2}$

RESUMO: O objetivo desse estudo foi determinar quais as principais manifestações da papilomatose confluente e reticulada e sua resposta ao tratamento com isotretinoína oral. Métodos: O presente estudo refere-se a uma descrição de um relato de caso, sendo um estudo observacional de aspecto descritivo com caráter qualitativo, o qual tem como objeto de estudo a terapia medicamentosa com isotretinoína oral em paciente diagnosticado com papilomatose reticular e confluente. O estudo foi realizado no Centro de especialidades Frei Damião, localizado na cidade de Patos no estado da Paraíba, onde o paciente será acompanhado ambulatorialmente. Descrição do relato: A paciente do relato em questão procurou o serviço de dermatologia da NEUREDERM, apresentando manchas escurecidas em dorso e nas pernas desde os 15 anos de idade. Em seu quadro clínico foram identificadas máculas acastanhadas com leve descamação em região do dorso, principalmente região interescapular e nas pernas desde a adolescência, tendo sido realizado o diagnóstico de papilomatose confluente e reticulada. Conclusão: o tratamento com isotretinoína oral tem mostrado eficácia no controle da progressão das lesões quando o tratamento com antibióticos como minociclina não apresentarem melhora.

Palavras chave: Papilomatose. Isotretinoína. Relato de caso.

ABSTRACT: The objective this study was determinate the main manifestations of confluent and reticulated papillomatosis and its response to treatment with oral isotretinoin. Methods: The present study refers to a description of a case report, being an observational study of a descriptive aspect with a qualitative character,

\footnotetext{
${ }^{1}$ Graduanda em Medicina. Centro Universitário de Patos - UNIFIP, Patos, Paraíba, Brasil.

2 Médico Especialista em Dermatologia. Centro Universitário de Patos - UNIFIP, Patos, Paraíba, Brasil.
} 
which has as object of study the drug therapy with oral isotretinoin in a patient diagnosed with reticular and confluent papillomatosis. The study was carried out at the Frei Damião specialty center, located in the city of Patos in the state of Paraiba, where the patient will be followed up on an outpatient basis. Description of the report: The patient in the report in question sought the dermatology service of NEUREDERM, with darkened spots on the back and legs since she was 15 years old. In his clinical picture, brownish macules with slight desquamation were identified in the dorsal region, mainly the interscapular region and in the legs since adolescence. Conclusion: treatment with oral isotretinoin has been shown to be effective in controlling the progression of lesions when treatment with antibiotics such as minocycline does not show improvement.

Keywords: Papillomatosis. Isotretinoin. Case report. 


\section{INTRODUÇÃO}

A papilomatose confluente e reticulada foi exposta por Gougerot e Carteaud, dermatologistas franceses, em 1927, por isso sua definição também conhecida por papilomatose confluente e reticulada de Gougerot e Carteaud (RODRÍGUEZCARREÓN et al., 2008).

Segundo Ferreira, Diniz e Ferreira (2009), a sua etiologia é obscura, por isso muitas hipóteses foram levantadas para explicação da sua etiopatogenia, uma delas é nos casos de PCR (papilomatose confluente e reticulada) hereditária que é considerada uma genodermatose de ceratinização, explicada como um desarranjo na queratinização ou uma reação incomum a microorganismos da biota cutânea, tendo esta última causa como principal agente as leveduras lipofílicas do gênero Malassezia.

Outras teorias relatam ser uma reação incomum do hospedeiro a instalação do Pityrosporum orbiculare ou Staphylococcus formador de toxinas, explicado pela localização das lesões encontrar-se em áreas habitualmente colonizadas pelo organismo (CARNEIRO; DIAS; SILVA, 2008).

Adicionalmente alguns estudos também demonstraram relações endocrinológicas a exemplo da obesidade, intolerância à glicose/diabetes, hirsutismo, tireoidite, síndrome de Cushing, bem como ligação a fatores genéticos e fotossensibilidade, uma vez que decorrente da exposição solar, esse quadro tende a se agravar em épocas como o verão. Tem-se demonstrado também a tal distúrbio associações com atopias (CARNEIRO; DIAS; SILVA, 2008; LEITE et al., 2015).

Alguns ainda relacionaram a papilomatose confluente e reticulada com a carência de vitamina A ou ainda explicada como uma provável variante da amiloidose cutânea, que além desta entrar nos diagnósticos diferenciais da PCR podemos citar também a pitiríase versicolor, acantose nigricans, algumas apresentações de dermatites seborreicas e desordens na queratinização (BRENNER et al., 2014). 
A papilomatose é apontada como uma dermatose rara, descrita com o aparecimento lento e progressivo de lesões papulosas com descamação fina, de características verrucosa ou pontilhada, em torno de $5 \mathrm{~mm}$ de diâmetro, hiperpigmentadas, acastanhadas, formando placas, usualmente aderidas em região central do tronco, sobretudo em área intermamária, interescapular, epigástrica, axilas e pescoço, distribuindo-se de forma simétrica com uma disposição reticulada periférica (BERNARDES FILHO et al., 2014; LEE; LOO; TAN, 2018).

Possivelmente, as lesões podem se expandir para os ombros, pescoço e região púbica. As extremidades podem ser acometidas, porém em um percentual inferior; as regiões plantar e palmar e as membranas mucosas são usualmente poupadas (CARNEIRO; DIAS; SILVA, 2008).

Pode-se também perceber a presença ou não de prurido, sendo este ainda classificado em leve, moderado e grave, associado a um intenso desconforto. Dentre os exames atribuídos, a solicitação de exame micológico é mandatória, o emprego da lâmpada de Wood pode-se constatar coloração amarela fluorescente se houver a presença de fungo (MARTINS; ROCHA; SPIES, 2015).

A histopatologia não é específica, os achados mais frequentes referidos neste exame são: hiperceratose, ortoceratósica e papilomatose irregular, adelgaçamento da granulosa e acantose focal interpapilar. Ocasionalmente, os vasos da derme papilar podem apresentar um certo grau de dilatação, cercado de um infiltrado inflamatório de caráter linfocitário. Também podemos observar uma hiperpigmentação da camada basal sem alteração do número de melanócitos. Em casos de dúvida no diagnóstico, a histopatologia pode auxiliar (BRENNER et al., 2014).

Observou-se que a prevalência da papilomatose é encontrada mais comumente em mulheres, com uma incidência duas vezes maior em negros do que em brancos. Acomete especialmente jovens após a puberdade numa faixa etária dos 10 aos 35 anos, com uma idade média entre os 21 anos, em geral tem o seu pico no final da adolescência e início da vida adulta (FERREIRA; DINIZ; FERREIRA, 2009; MARTINS; ROCHA; SPIES, 2015).

Ainda não se foi elucidado um tratamento específico para tal patologia, inúmeros fármacos foram utilizados com resultados inconstantes, dentre os estudos 
analisados são retratadas opções terapêuticas com agentes tópicos, (ceratolíticos, derivados da vitamina $\mathrm{A}$ e $\mathrm{D}$, antimicrobianos) como Peróxido de benzoíla, lactato de amônio, ureia, tretinoína, clindamicina, hiposulfito de sódio e análogos de vitamina $D$, sistêmicos (antibióticos e retinóides) minociclina, etretinato e isotretinoína estão entre os mais utilizados. A utilização de antimicóticos tópicos ou sistêmicos pode-se levar em consideração, principalmente quando houver dúvida no diagnóstico diferencial com ptiríase versicolor (MARTINS; ROCHA; SPIES, 2015).

Com a escassez de estudos disponíveis na literatura, é relevante responder a seguinte pergunta: quais as principais manifestações da papilomatose confluente e reticulada encontradas e sua resposta ao tratamento com isotretinoina oral? Todavia, a maioria dos tratamentos estabelecidos obtiveram recidiva recorrentes com a interrupção do tratamento. A realização deste estudo justifica-se pela relevância dos casos para a prática clínica baseada em evidência, desta forma, a evolução terapêutica do paciente implica a tomada de decisão clínica a partir da sintomatologia e terapêutica indicada.

\section{MÉTODOS}

Trata-se de uma descrição de um relato de caso, sendo um estudo observacional de aspecto descritivo com caráter qualitativo, o qual tem como objeto de estudo a terapia medicamentosa com isotretinoína oral em paciente diagnosticado com papilomatose reticular e confluente. $O$ estudo foi realizado no Centro de especialidades Frei Damião, localizado na cidade de Patos no estado da Paraíba, onde o paciente será acompanhado ambulatorialmente.

Pode-se definir o relato de caso como uma descrição detalhada de um caso clínico ou mais, possuindo características importantes sobre sinais, sintomas e outros aspectos do paciente, além de relatar quais procedimentos terapêuticos foram utilizados, bem como o desenrolar do caso, com sua evolução e desfechos clínicos. Pode ser caracterizado como um estudo observacional, prospectivo, com caráter descritivo e de abordagem qualitativa. Relatos e séries de casos configuram-se 
como o melhor método que permite aos profissionais da saúde descreverem cientificamente sua experiência clínica sobre determinado tema, contribuindo para o progresso do conhecimento médico sobre inúmeras enfermidades, sejam elas raras ou comuns na prática clínica (PARENTE; OLIVEIRA; CELESTE, 2010; KIENLE; KIENE, 2011).

As informações apresentadas nos relatos de casos possuem valor central na descoberta de novas doenças, em seus tratamentos, efeitos inesperados, benefícios ou malefícios identificados e efeitos colaterais para a prática clínica. Esse tipo de estudo constitui uma importante ferramenta no progresso do exercício da medicina, podendo disponibilizar importantes informações que podem ser utilizadas por outros profissionais, ou mesmo achados que podem ser contestados e melhor debatidos no meio médico. Para tanto, é necessário que os relatos de casos possuam uma ótima construção e argumentação ao longo de seu desenvolvimento, com excelente qualidade na sua elaboração e exposição, garantindo conteúdo e sequência apropriados, assim como estudos clínicos (PARENTE; OLIVEIRA; CELESTE, 2010; KIENLE; KIENE, 2011).

Para a pesquisa descrita no presente relato, o estudo dos casos foi efetuado no Centro de Especialidades Frei Damião, localizado na cidade de Patos - PB, no período de fevereiro a abril de 2020. A paciente do caso tem 33 anos, sexo feminino, casada, enfermeira, residente e precedente da cidade de Patos - PB. Recebeu diagnóstico de papilomatose confluente e reticulada e realizou tratamento inicialmente com minociclina, o qual, diante de ausência de resposta satisfatória, foi substituído pela isotretinoína oral. Após a aprovação pelo Comitê de Ética e Pesquisa (CEP) do Centro Universitário de Patos - UNIFIP, com número do parecer do CAAE 4.496.215, a paciente foi contatada e assim foi realizado esclarecimentos sobre os objetivos da pesquisa, com posterior assinatura do Termo de Consentimento Livre e Esclarecido (TCLE) e o Termo de Assentimento. Com isso, os trâmites que envolvem a pesquisa foram realizados condizentes às normas da Resolução número 466/2012 e 510/16 do Conselho Nacional de Saúde - Pesquisa em Ciências Humanas e Sociais.

As informações foram coletadas a partir de prontuários eletrônicos e por meio de entrevistas, com ênfase na anamnese, investigação clínica, localização da 
papilomatose, sua forma clínica, exames complementares laboratoriais e histopatológicos necessários para avaliação e seguimento, além do tratamento realizado e a evolução clínica da paciente. Os dados foram digitalizados e sistematizados no programa Microsoft Word 2016®, com posterior análise qualitativa e interpretação crítica.

Por fim, os estudos utilizados para a discussão deste trabalho foram extraídos das seguintes bases de dados Biblioteca Virtual em Saúde (BVS), Medical Publisher (PUBMED), Google Scholar e MEDLINE, obtidos por meio dos descritores "Papillomatosis" AND " Isotretinoin " AND "Case report ".

\section{RELATO DE CASO}

Paciente M.F.L., 33 anos, sexo feminino, casada, enfermeira, residente e precedente da cidade de Patos - PB. A paciente procurou o serviço de dermatologia da NEUREDERM, apresentando manchas escurecidas em dorso e nas pernas desde os 15 anos de idade.

Em seu quadro clínico foram identificadas máculas acastanhadas com leve descamação em região do dorso, principalmente na região interescapular e nas pernas.

Relata que já fez uso de vários cremes antifúngicos e de corticoide, sem melhora das lesões. Nega prurido, ardência, dor ou outros sintomas associados. Discorre que as lesões pioram em épocas quentes do ano e ficam mais descamativas.

Em seu manejo clínico foi realizado diagnóstico de Papilomatose Reticular e Confluente e iniciado tratamento com minociclina 100mg por 30 dias associado a Ácido fusídico, porém não houve melhora do quadro.

Com isso, realizou-se mudança do tratamento para isotretinoína $20 \mathrm{mg} 1 \mathrm{xdia}$, apresentando boa resposta já no primeiro mês de tratamento.

Após um seguimento de 6 meses de tratamento com essa nova modalidade, observou-se melhora significativa e considerável das lesões. 
Imagens do aspecto das lesões antes do tratamento

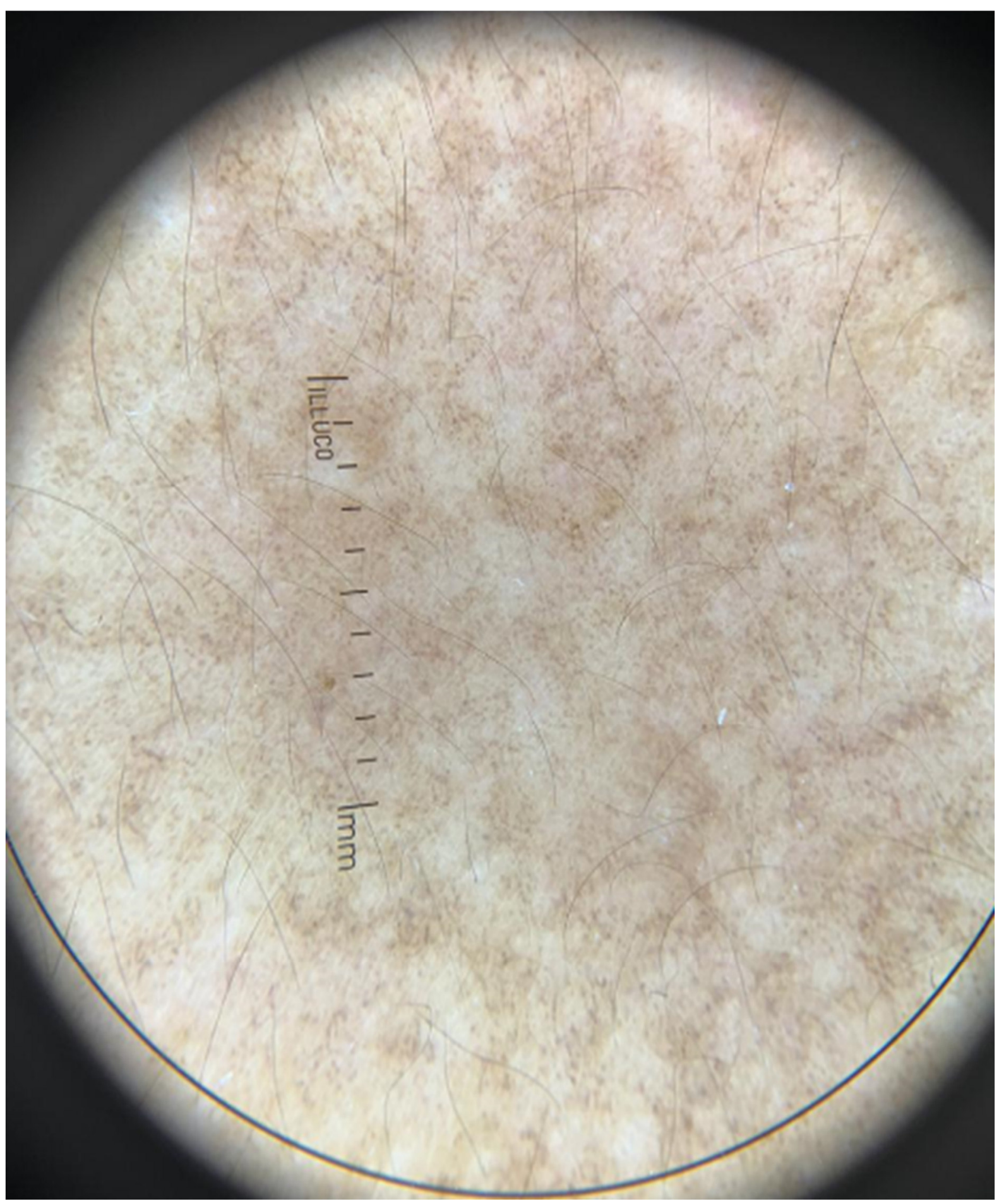




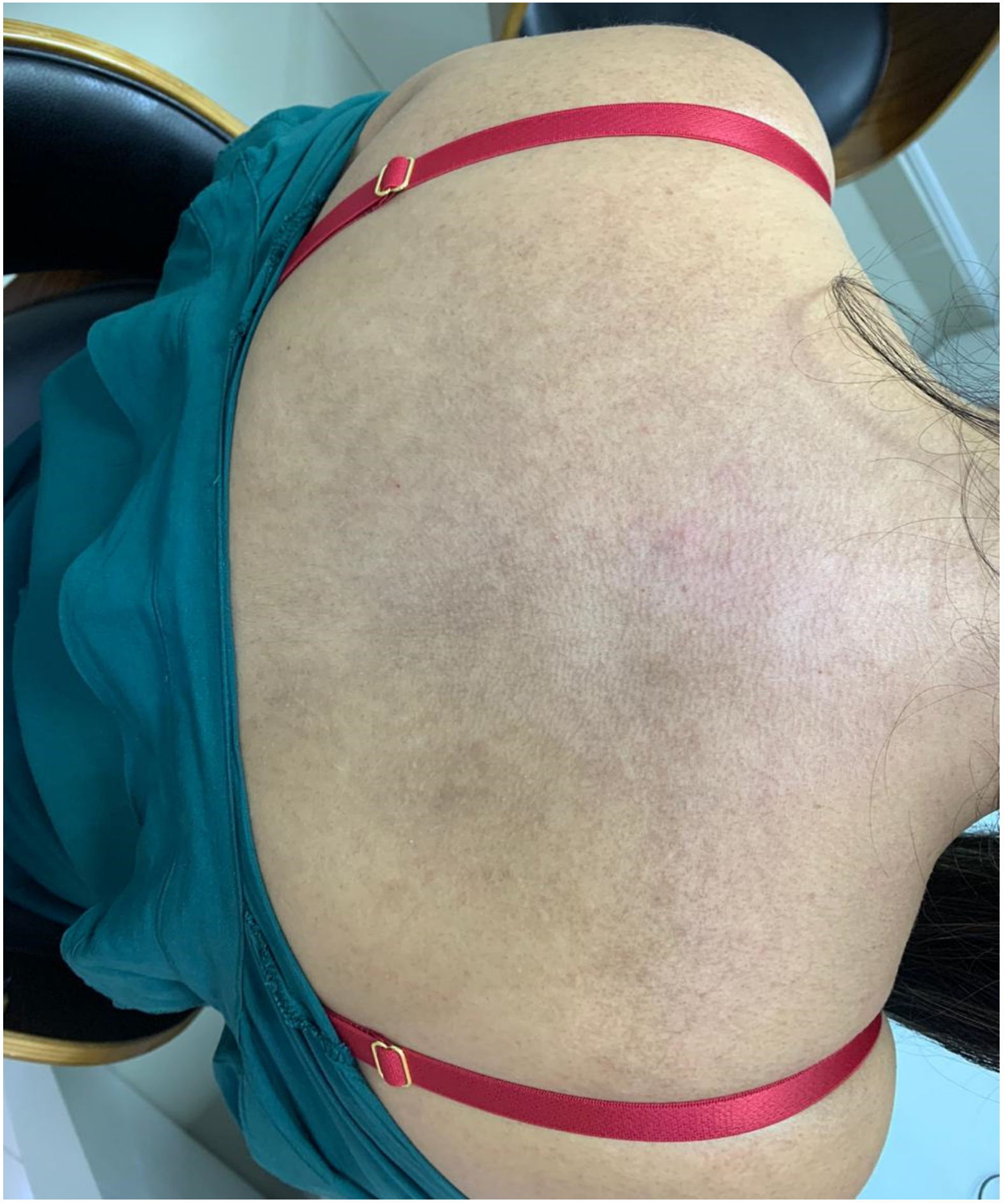




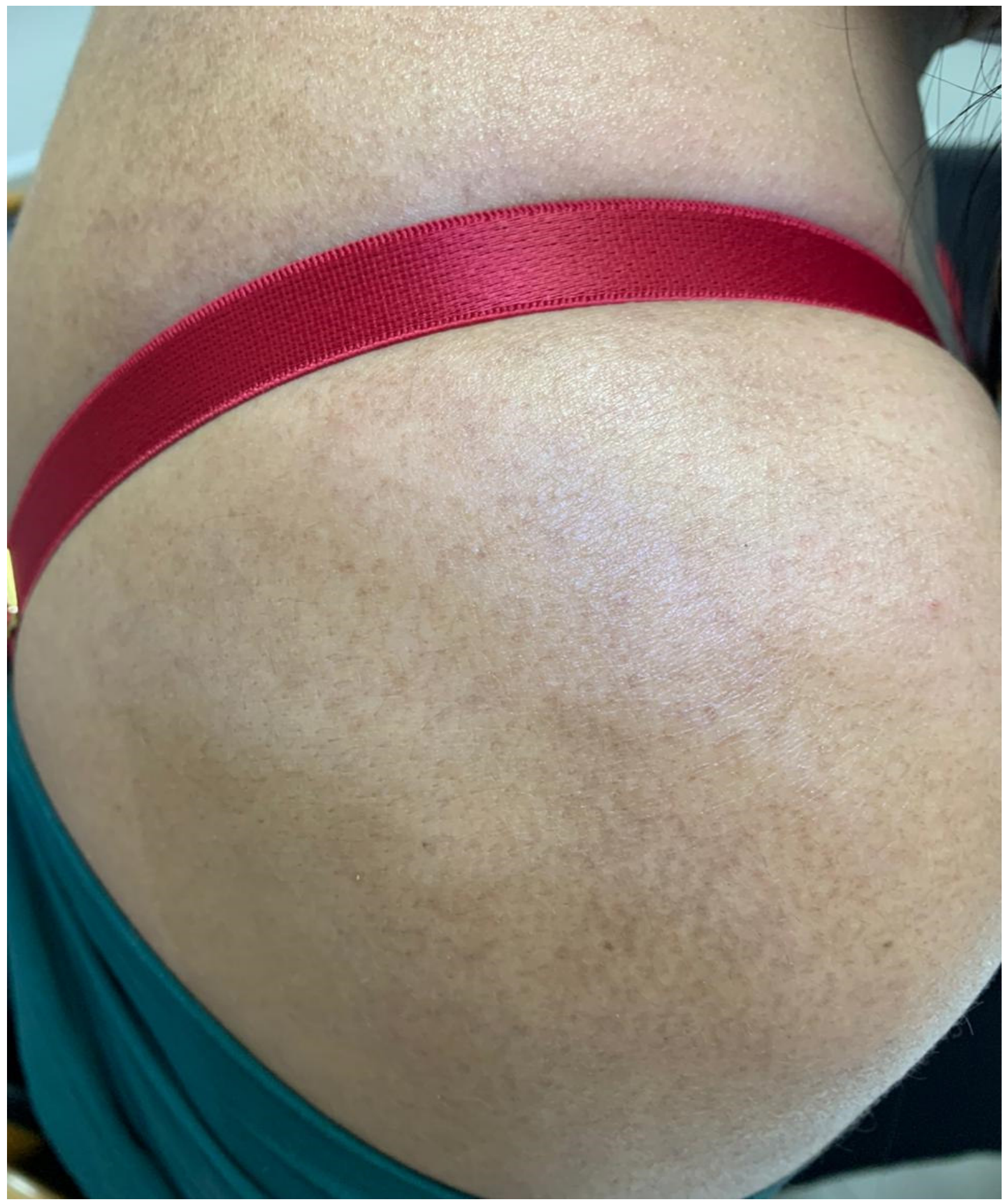


Aspecto das lesões após três meses com tratamento com isotretinoína $20 \mathrm{mg}$ 1xdia

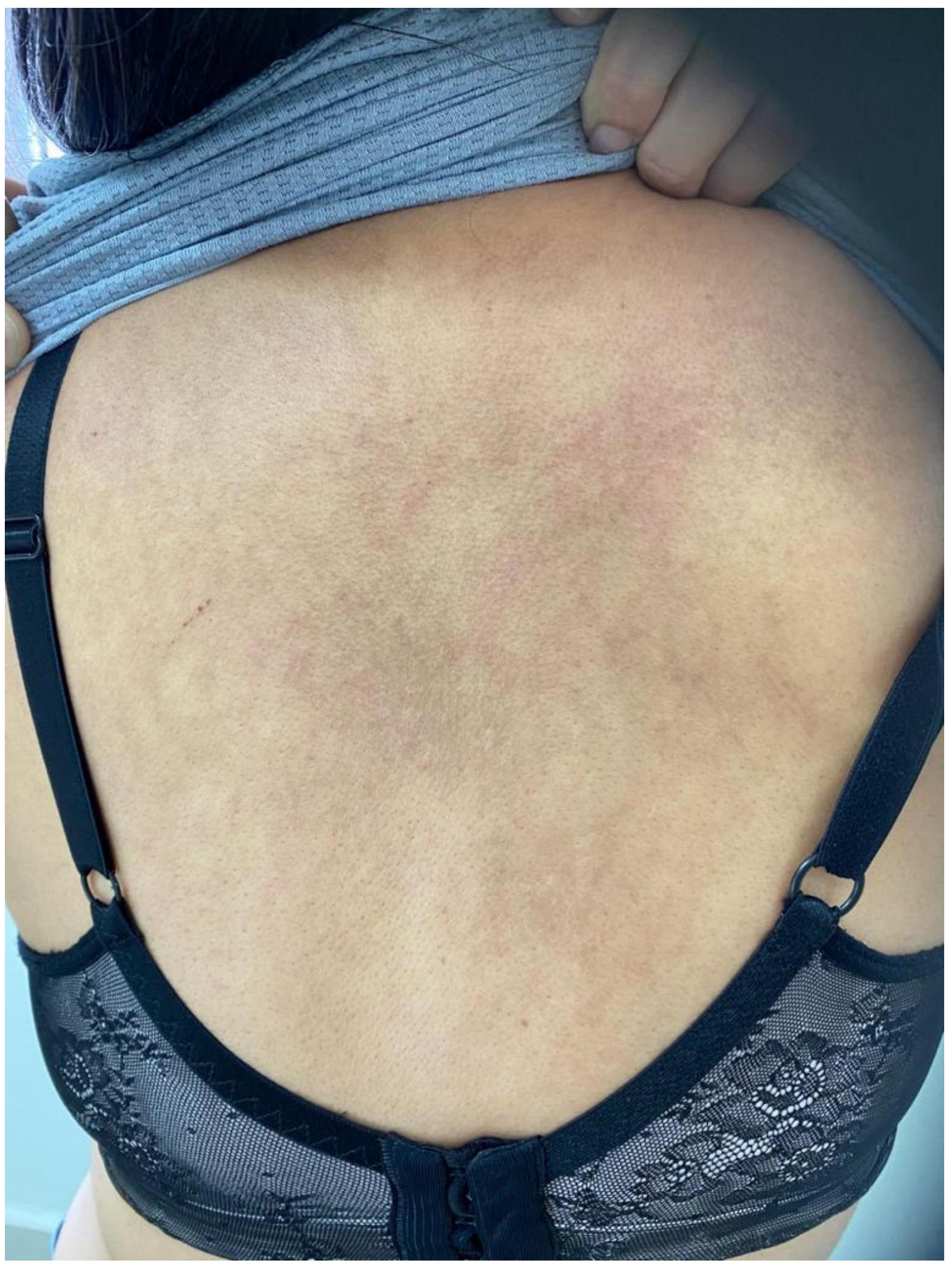




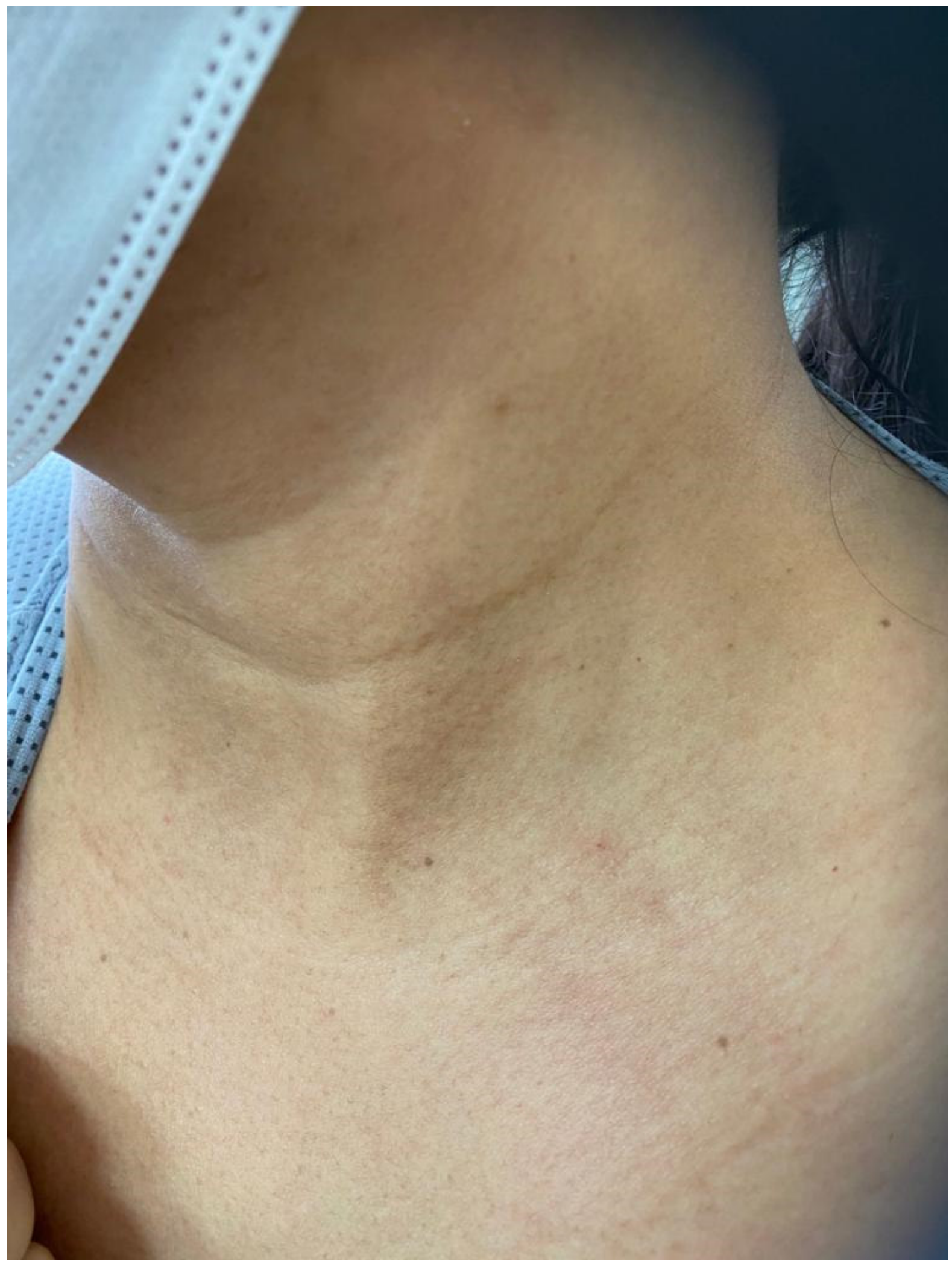




\section{DISCUSSÃO}

A papilomatose confluente e reticulada (PCR) é um distúrbio de pele incomum com etiologia ainda desconhecida, caracterizada por pápulas hiperceratóticas confluentes na área central e reticuladas hiperpigmentadas nas regiões periféricas. Os critérios diagnósticos propostos para sua identificação incluem: (I) os achados clínicos de máculas marrom escamosas e manchas, com, pelo menos, alguns parecendo reticulado e papilomatoso; (II) o envolvimento da parte superior do tronco e pescoço; (III) Coloração negativa de fungos de escalas; (IV) ausência de resposta ao tratamento antifúngico; e $(\mathrm{V})$ excelente resposta à minociclina. (BRENNER et al., 2014; JO et al., 2014; CHONG; LIM; TEY, 2016; BLANCO et al., 2019).

A lesão elementar da papilomatose confluente e reticulada é caracterizada por uma pápula de pequeno tamanho verrucosa, plana, pouco saliente, com uma coloração variável, hipocrômica, rósea ou acastanhada, com tamanho de até $5 \mathrm{~mm}$. Elas tornam-se confluentes no centro e adquirem aspecto reticulado na periferia, formando placas com limites imprecisos, ligeiramente descamativas e ocasionalmente assumem um aspecto pseudo-atrófico. As lesões se iniciam nas regiões interescapular, epigástrica e intermamária, podendo progredir até a nuca, região cervical lateral, ombros, axilas e região pubiana. São geralmente assintomáticas, podendo haver um leve prurido (BRENNER et al., 2014; MARTINS; ROCHA; SPIES, 2015).

É provável que exista predisposição genética para o desenvolvimento da PCR, uma vez que casos familiares estão descritos na literatura. Acomete todas as raças, gêneros e faixas etárias, tendo predileção por adolescentes e adultos jovens do sexo feminino. Existe também correlação entre atopias e endocrinopatias, com especial atenção àquelas que cursam com resistência à ação da insulina: obesidade, síndrome dos ovários policísticos e diabetes mellitus (DAVIS; WEENIG; CAMILLERI, 2005; BLANCO et al., 2019).

$\mathrm{Na}$ análise histopatológica, mesmo que não haja elevada especificidade, é possível identificar hiperceratose associada com acantose focal interpapilar, papilomatose e 
hiperpigmentação da camada basal, sem existir aumento do número de melanócitos, além de adelgaçamento da granulosa. Na derme papilar, é possível identificar infiltrado linfocitário perivascular superficial, rodeado por vasos ectasiados (BRENNER et al., 2014; BLANCO et al., 2019).

Histopatologicamente, os diagnósticos diferenciais incluem a acantose nigricans, as variantes da ceratose seborreica, o nevo epidérmico do tipo não inflamatório, a doença de Dowling-Degos e o nevo de Becker. À microscopia eletrônica observa-se aumento da camada de células transicionais entre a camada granulosa e a córnea. Esse fato pode definir a PCR como uma desordem da queratinização de áreas focais da pele, sem elucidar se essa alteração seria primária ou secundária (BRENNER et al., 2014).

As lesões iniciais dessa doença dérmica, quando estão localizadas exclusivamente nas regiões de pregas, são comumente confundidas com acantose nigricans (AC), mas a PCR extrapola as áreas classicamente afetadas pela AC para lesões generalizadas pelo tronco e se distingue também pela característica pontilhada das suas pápulas verrucosas. O padrão reticulado encontrado na periferia da lesão e a confluência central selam a distinção das entidades clínicas (GONZÁLEZ et al., 2008; BLANCO et al., 2019).

A papilomatose confluente e reticulada pode gerar estresse psicológico, sentimentos de constrangimento e deve ser reconhecida para evitar essas consequências nos pacientes. O correto diagnóstico, orientação e tratamento devem ser prontamente estabelecidos no manejo clínico (DAVIS; WEENIG; CAMILLERI, 2005).

Atualmente, a modalidade terapêutica que melhor apresenta resultados no tratamento desse distúrbio é o uso de antibióticos orais, tendo sua eficácia comprovada em estudos prospectivos e retrospectivos. Além disso, a redução de peso também pode estar associada com a regressão das lesões. A boa resposta ao uso da minociclina é esperada, entretanto ela não é constante (BLANCO et al., 2019).

Em estudo realizando tratamento com minociclina oral $50 \mathrm{mg}$ duas vezes ao dia durante 6 semanas em 9 pacientes com papilomatose confluente e reticulada, observou-se 90 a 100\% de resposta em 7 dos 9 doentes, porém com recorrência em 
3 e que responderam a novo tratamento com minociclina. Dessa forma, é possível afirmar que esse medicamento é eficaz no tratamento da PCR, muito provavelmente devido às suas propriedades anti-inflamatórias, imunossupressora e anti-proliferativa (CHONG; LIM; TEY, 2016; BLANCO et al., 2019).

Em um estudo prospectivo com 39 pacientes com PCR, 22 foram submetidos ao tratamento com minociclina oral. Desses, 14 apresentaram resposta completa e 4 (22\%) uma resposta parcial. Os relatos existentes na literatura reforçam a eficácia da minociclina e de outras ciclinas para o tratamento desse distúrbio dérmico (DAVIS; WEENIG; CAMILLERI, 2005; BLANCO et al., 2019).

O tratamento com minociclina oral $100 \mathrm{mg}$ ao dia mostrou-se eficaz e com boa resposta terapêutica ao longo de um período de 8 a 10 semanas, sem apresentar recidivas após 12 meses. Entretanto, essa eficácia não é constante e pode ser diferente nos pacientes tratados (BRENNER et al., 2014; CHONG; LIM; TEY, 2016).

É válido ressaltar, ainda, que outros antibacterianos tais como ácido fusídico, eritromicina, azitromicina e claritromicina também apresentaram eficácia no tratamento da PCR, reforçando a importância terapêutica do uso dessa classe de medicamentos nessa doença. Além deles, derivados orais e tópicos da vitamina $D$ e retinoides tópicos também podem ser utilizados como complementação terapêutica e ainda há a possibilidade do tratamento com isotretinoína nos casos refratários. Esse amplo espectro de opções terapêuticas pode ser explicado pela etiopatogenia multifatorial da PCR, com diferentes mecanismos de ação (BLANCO et al., 2019).

As respostas aos retinoides sustentam a teoria de a doença ter como causa alguma desordem da queratinização. Tem sido preconizado o uso de isotretinoína oral um a $2 \mathrm{mg} / \mathrm{kg} / \mathrm{dia}$, com resposta favorável em dois meses (FERREIRA; DINIZ; FERREIRA, 2009; CHONG; LIM; TEY, 2016).

Corroborando os dados da literatura apresentados nesse estudo, a paciente do relato em questão não apresentou melhora do quadro com o uso de minociclina $100 \mathrm{mg}$ ao dia durante 30 dias associado com ácido fusídico, confirmando os dados de que a eficácia de ambos antibióticos varia em cada paciente.

Entretanto, a paciente apresentou resposta satisfatória com um medicamento utilizado nos casos refratários, que é a isotretinoína $20 \mathrm{mg}$ uma vez ao dia, já apresentando melhora no primeiro mês de tratamento, além de ter apresentado 
melhora significativa das lesões ao longo de 6 meses de tratamento. No entanto, ainda é necessário acompanhar o seguimento da paciente para observar recidiva das lesões e avaliar se será necessário tratamento para prevenção das lesões.

\section{CONSIDERAÇÕES FINAIS}

Levando em consideração os dados apresentados, pode-se inferir que a papilomatose confluente e reticulada é uma rara condição dermatológica associada a uma etiopatogenia multifatorial e associada com atopias e endocrinopatias, tendo maior prevalência em adolescentes e adultos jovens, devendo ser reconhecida, diagnosticada e recebendo orientações adequadas aos pacientes, além de um correto manejo clínico.

É essencial considerar os diagnósticos diferenciais, os aspectos clínicos e a semelhança dos sinais e sintomas com outras condições dermatológicas como forma de evitar condutas inadequadas e reações adversas indesejadas aos pacientes.

O presente relato de caso buscou esclarecer as principais manifestações clínicas dessa condição clínica, trazendo atualizações sobre o correto diagnóstico e manejo clínico, além da eficácia do tratamento com isotretinoína oral. Seu uso tem mostrado eficácia no controle da progressão das lesões quando o tratamento com antibióticos como minociclina não apresentarem melhora.

Sugere-se para estudos futuros uma melhor correlação do uso da isotretinoína, bem como age seu mecanismo de ação, evitando a progressão da doença e o estabelecimento de um protocolo de tratamento para a papilomatose confluente e reticulada para facilitar as condutas clínicas.

\section{REFERÊNCIAS BIBLIOGRÁFICAS}

BERNARDES FILHO, F.; QUARESMA, M. V.; REZENDE, F. C.; KAC, B. K.; NERY, J. A. C.; AZULAY-ABULAFIA, L. Confluent and reticulate papillomatosis of Gougerot-Carteaud and obesity: dermoscopic findings. Anais Brasileiros de Dermatologia, v. 89, n. 3, p. 507-509, 2014. 
BLANCO, N. C.; POSES, S. C.; MARRA, A. L. F. F.; BASTOS, J. C.; AMORIM-FILHO, R. M.; AMORIM, G. M. Papilomatose Reticulada e Confluente de Gougerot-Carteaud: melhoria significativa e sustentada das lesões com minociclina oral. Journal of the Portuguese Society of Dermatology and Venereology, v. 77, n. 3, p. 253-256, 2019.

BRENNER, F. A. M.; MESQUITA, L. A. F.; HAUSCHILD, J B.; SIMEÃO, A. G. Papilomatose confluente e reticulada de Gougerot e Carteaud: boa resposta à minociclina em dois casos. Surgical \& Cosmetic Dermatology, v. 6, n. 3, p. 293-296, 2014.

CARNEIRO, F. A. R.; DIAS, L. M.; SILVA, A. C. M. S. da. Papilomatose confluente e reticulada de Gougerot-carteaud: Relato de Caso. Revista Paraense de Medicina, v. 22, n. 1, p. 63-68, 2008.

CHONG, W.; LIM, J. H.; TEY, H. L. Confluent and reticulated papillomatosis: diagnostic and treatment challenges. Clinical, Cosmetic and Investigational Dermatology, v. 9, p. 217-223, 2016.

DAVIS, M. D. P.; WEENIG, R. H.; CAMILLERI, M. J. Confluent and reticulate papillomatosis (Gougerot-Carteaud syndrome): a minocycline-responsive dermatosis without evidence for yeast in pathogenesis. a study of 39 patients and a proposal of diagnostic criteria. British Journal of Dermatology, v. 154, n. 2, p. 287-293, 2005.

FERREIRA, L. M.; DINIZ, L. M.; FERREIRA, C. J. M. Papilomatose confluente e reticulada de Gougerot e Carteaud: relato de três casos. Anais Brasileiros de Dermatologia, v. 1, n. 84, p. 78-81, 2009.

GONZÁLEZ, M. C.; SÁNCHEZ, B. M.; MUIÑOS, E. L.; SOTOS, C. L. H.; CARREIRA, J. M. Cacharrón. Papilomatosis reticulada y confluente de Gougerot-Carteaud. Anales de Pediatría, v. 68, n. 6, p. $628-629,2008$.

JO, S.; PARK, H. S.; CHO, S.; YOON, H. Updated Diagnosis Criteria for Confluent and Reticulated Papillomatosis: a case report. Annals of Dermatology, v. 26, n. 3, p. 409-410, 2014.

KIENLE, G. S.; KIENE, H. Como escrever um relato de caso. Arte Médica Ampliada, v. 31, n. 2, p. 34-7, 2011.

LEE, S. W.; LOO, C. H.; TAN, W. C. Confluent and reticulated papillomatosis: Case series of 3 patients from Kedah, Malaysia and literature review. The Medical Journal of Malaysia, v. 73 n.5, p. 338-339, 2018.

LEITE, J.; ABREU, M.; MARTINS, M. M.; TEIXEIRA, M. Papilomatose reticulada e confluente de Carteaud e Gougerot: apresentação na adolescência. Revista Nascer e Crescer, v. 24, n. 4 , p. 171-3, 2015.

MARTINS, P. H. T.; ROCHA, L. B.; SPIES, J. Papilomatose confluente e reticulada de gougerot e carteuad: relato de caso. Arquivos Catarinenses de Medicina, v. 44, n. 4, p. 57-62, 2015.

PARENTE, R. C. M.; OLIVEIRA, M. A. P.; C. R. K. Relatos e série de casos na era da medicina baseada em evidência. Brazilian Journal of Videoendoscopic Surgery, v. 3, n. 2, p. 67-70, 2010.

RODRÍGUEZ-CARREÓN, A. A.; ARENAS-GUZMÁN, R.; FONTE-ÁVALOS, V. Papilomatosis reticulada y confluente de Gougerot-Carteaud. Un caso con excelente respuesta a minociclina. Gaceta Médica de México, v. 144, n.1, p. 67-70, 2008. 